\title{
INDIVIDUALISTIC APTITUDE AND BIOFEEDBACK ON IMPROVEMENT OF COORDINATION IN YOUNG ATHLETES
}

\author{
Dr. Srilekha Saha, Dr. Soumendra Saha and Nurfarah Ezzaty Binti Mohd Zahir \\ Exercise \& Sports Sciences Programme. School of Health Sciences, PPSK \\ Universiti Sains Malaysia Kota Bharu, Kelantan, Malaysia.16150. \\ author email: srilekha@kk.usm.my
}

\begin{abstract}
Sports cognition encompasses the primary affective-motivational aspect related to primordial fight-or flight responses, which are essentially the precursors for both the BAS (behavioural activation system the reward system) and BIS (behavioural inhibition system- the punishment or fear-eliciting system). In Asian and especially South-Asian perspective, impulsivity and aggressive out-bursts are by and large considered as conduct disorders, thus more acceptable docile tendency in children and pre-adolescent lead them to a cognitive-motivational make-up of BIS orientation. With such a background the present study was carried out to identify the extent of cognitive-affective competence of the skilled competitive players in enhancing bilateral motor coordination required for high sport performance. Eighty-one high performing female ball game players matched with their performance-specific motor coordination ability, were categorised into three differential groups based on their psychobiological competence, viz; Group A- consisted of twenty-seven players diagnosed with moderate level of sympathovagal balance; Group $B(N=27)$ - consisted of twenty-seven players diagnosed with discordant sympathovagal balance, while Group $C(n=27)$ were identified as having high sympathovagal balance. Thereafter, players of Group B \& C were introduced to training of skin-conductance biofeedback tailored for musculoskeletal enhancement (20 min.s/ day; three days/ week for twelve weeks). Mid-term analyses of motor coordination as well as the post-intervention analyses (carried out after the twelfth week) revealed that players having higher sympathovagal balance had higher efficiency in modulation of muscle tension as well as in perceptual -motor adaptation, which have prompted them to have enhanced bilateral and visual-motor coordination compared to their counterparts.
\end{abstract}

Keywords: Biofeedback, Motor Coordination, Sport performance

\section{INTRODUCTION}

Sport performance in elite level has long been considered as the combination of some salient physical, physiological, social and psychological factors, which interplay between them to produce excellence in sports behaviour. Sports requiring faster reactions to visual stimulation require faster sensory processing and precise cognitive judgements that culminate in accurate and appropriate-most reactions.

Empirical supports here have alternatively postulated the use of anticipation by the elite players to circumvent the reaction time delays inherent in every aspect of sport activity (McLeod, 1987) and to optimize their visual search strategies to make best use of early information (Land \& McLeod, 2000). There exist reasonable amount of evidence to indicate that early pick-up of information from the opponent's movement pattern is integral to skilled performance (Abernethy \& Russell, 1984; Penrose \& Roach, 1995; McRobert \& Tayler, 2005; Renshaw \& Fairweather, 2000). But these researches have number of limitations (Müller et al., 2006). First, the majority of studies have typically included skilled 
players who did not have adequate international exposure, and more over these players were compared with the novices.

Another aspect of significant importance is that the expert players always pay detailed attention to the relevant cues, and only the field-relevant information matched with cognitive schema (already structured temporal and spatial cues) gets immediately processed with the introduction of optimum cortical arousal initiated by ascending reticular activating system (ARAS) which is mostly essential for cognitive processing (Eysenck, 1982). Optimum excitatory ARAS would facilitate in faster reactions, since it keeps up a sports performer ready to react to any incoming stimulus. The RAS also has descending tract, which influences motor functions. There is good reason to believe in that the descending tract of the RAS may be in part responsible for the improvement in the speed and coordination of reactions under higher levels of arousal (Franken, 1998). Thus apart from anticipation, it seems important to identify the role of the sensory - perceptual discrimination ability of the players in augmenting faster reactions.

The highly skilled players have the ability to read and interpret complex situations quickly and to initiate decisive action. The faster the simple muscular reaction and movement time of the individual, the quickly will be responses to complex situations (Saha et al 2003; Saha et al 2005a). In cricket, apart from reaction and movement time, accurate anticipation of relevant visual cues and the consequent whole body reaction seems absolutely essential to conceptualise different facets of expert performance (Togari and Takahashi, 1977 and Suzuki et al. 1988).

Here the matter of concern for the sport psychology researchers in the fields of athletic events appear with the question of the relative contribution of the intricate psychological and psychobiological processes in ensuring excellent reaction performance. Numerous studies pointed out the importance of ARAS only in controlling excellent reaction performance (Franken, 1998), while a lot others pointed out the need for consideration into movement related motor coordination (Heyman 1982 and Tenenbaum et al 1992) and others considered role of involvement of cortical and autonomic activation as cognitiveemotional mediator component as more important factor for concern (Saha et al 2003; Saha et al 2005a and Saha et al 2005b).

Authors of the present study on the contrary, are trying to point out to their concern over the methodological issues related to the assessment and analyses of the reaction performances in athletics. Apart from that, of vital importance is the question of whole-body reaction performance along with the simultaneous assessment of other correlated and influencing psychobiological mediators are also considered as the significant aspect of research interest. Introduction of few relevant psychobiological measures such as measures of tonic electrodermal activity as index of emotionality substantiated by the autonomic arousal modulation and the orienting activity in experimental models to fit in correlation analyses would provide the researchers with relevant information related to faster reaction performance toward achievement of performance excellence. To date, laboratory-based analytical researches incorporating objective and direct measures of performance that could be served as predictors of excellent reaction and movement performance, is scarce, and available researches are either not dealt with direct and objective measures, or done with variables which are detected as having source of multicolinearity, and hence are not capable of predicting process-related shared aetiology behind excellent reaction ability related to successful athletic performance.

With such a background, the present study would focus on identifying-

1. Whether orienting amplitude can predict changes in coordination ability in the players; 
2. Whether autonomic regulation indexed by the tonic skin conductance can predict changes in movement coordination in the players;

3. Whether skin conductance biofeedback intervention can facilitate in orienting reflex activity and can predict changes in movement coordination in the players.

\section{MATERIALS AND METHODS}

\section{PARTICIPANTS}

[1] -- Saturday, March 29, 2014 -- 08:41:00

F tests - ANOVA: Repeated measures, within-between interaction

Analysis: A priori: Compute required sample size

$\begin{array}{lll}\text { Input: } & \text { Effect size f } & =0.20 \\ & \text { a err prob } & =0.05 \\ & \text { Power (1- } \beta \text { err prob) } & =0.95 \\ \text { Number of groups } & =3 \\ \text { Number of measurements } & =3 \\ \text { Corr among rep measures } & =0.5 \\ \text { Nonsphericity correction } \varepsilon & =1 \\ \text { Output: } \quad \text { Noncentrality parameter } \lambda & =19.4400000 \\ \text { Critical F } & =2.4296250 \\ \text { Numerator df } & =4.0000000 \\ \text { Denominator df } & =156 \\ \text { Total sample size } & =81 \\ \text { Actual power } & =0.9531436\end{array}$

Eighty-one consistently high performing female ball-game players (aging between 19.2 and 21.8 years, mean age $=20.5$ and SD $=1.19$ ), selected as the National development cadets by the respective selectors, volunteered as the participants in this study. These athletes were representing nine provincial teams and were selected by the respective National selectors of the Republic of Malaysia (Senior National and the Selected Development Squad listed as Malaysia Probable for the forthcoming Malaysia Games).

Previous data were collected on the afore-mentioned players during a period of more than one and half years (since May 2010 up to the October 2013, mostly on the basis of available long-term record of their reaction ability judged in the laboratory of sport psychology in the Universiti Sains Malaysia - by employing the Precision Reaction and Movement Timer; Bassin Anticipation Timer and Whole-body Movement Timer - Lafayette Instrument Corporation, Illinois, USA 2001). Thus on the basis of the long-term records of psychological measures and on the basis of their pre-inclusion reaction performances, the inclusion criterion for the purpose of present study was set.

\section{MATERIALS AND MEASURES}

1. Reaction Movement Timer Apparatus (Lafayette Instrument Corporation, USA 2001) was used to assess both the visual and auditory reaction and movement time of the participants.

1. Photoelectric Rotary Pursuit Apparatus (Lafayette Instrument Corporation, USA 2001) were used to assess both the visual and auditory whole -body reaction time of the participants.

2. Skin Conductance Apparatus (ProComp5 Infinity, USA 2013) was used to assess the extent of autonomic regulation as index of emotionality in the participants.

3. Rorschach Ink blot-test (RIB) was administered to evaluate inner emotional core components of the ball-game players. 


\section{PROCEDURE}

Previous records of the reaction performances were available in the data bank with the researchers of the present study, and for all of the psychomotor (such as reaction and movement timeRT \& MT) and psychophysiological analyses of the present study (autonomic regulation and orienting amplitude; recovery time etc.) employing measures of skin conductance activities- Sc), all the participants were assessed in the laboratory of sport psychology in the Universiti Sains Malaysia, and for the simulated reaction performances (particularly related to the movement coordination), assessments were done in the Sport Complex of the Universiti Sains Malaysia. Assessment of movement coordination for the athletes were planned mostly simulating the relevant competitive situations, in which players were required to display coordinated movement responses to some visual signal cues presented by accommodating bilaterally symmetric postural; motor and movement control. Accuracy in the successful-most coordination was considered as the data for the coordination performances. All of these assessments were done following standard procedures (methodology detailed in the Saha et al 2005a).

After the pre-intervention or baseline assessment, participants of groups B \& C were assigned to Skin Conductance (Sc) biofeedback intervention training following an identical intervention protocol viz., 20 min.s/day, 3 days per wk., 12 weeks, while the players of $\mathrm{Gr}$. A, who were observed to have moderate level of sympathovagal balance, remained engaged in their day-today activities. Special care was taken to monitor the activities of the players of Gr. A, so that they cannot engage themselves in coordination enhancing or musculo-skeletal skill

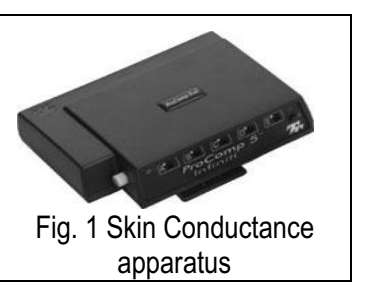
enhancing activities. Thereafter at the end of the intervention of the $12^{\text {th }}$ week, all of the players were assessed with all of the afore-mentioned parameters for the post-intervention analyses.

The data were treated with SPSS 20.0 statistical software for identification of the normality index. In accordance with the extent of skewness, wherever required, normality transformations were done with squared and log conversions. Thereafter reports on correlation analyses, prompted the authors to look into prediction analyses, and with present types of data both multiple linear and nonlinear (Polynomial Regression analysis) by employing both squared and cubic transformations of the centralised version of predictor variables, wherever needed could be of the best statistical model to fit in. Polynomial Regression Analysis was done to identify how far the different psychophysiological variables (autonomic regulation and orienting reflex information obtained from skin conductance measures) contribute in the shared aetiology of excellence in reaction performance.

\section{RESULTS}

Measures of psychological (cognitive-emotional) manifestations as well as psychobiological and psychomotor parameters are summarised in the table of descriptive statistics (Table-1). Means and standard deviations of the variables measured amongst the participants of the three groups are tabulated along with the existent significance of difference between them on the variables measured.

Table 1 - Descriptive measure and significance of pre-existing variance amongst the three groups

\begin{tabular}{|c|c|c|c|c|c|c|c|c|c|c|c|c|c|c|}
\hline \multirow[t]{2}{*}{ 을 } & \multicolumn{2}{|c|}{$\begin{array}{l}\text { Agility } \\
\text { (in M. } \\
\text { Seconds) }\end{array}$} & \multicolumn{2}{|c|}{$\begin{array}{c}\text { Tonic Skin } \\
\text { Conductance } \\
\text { (Log micro } \\
\text { mhos) }\end{array}$} & \multicolumn{2}{|c|}{$\begin{array}{c}\text { Orienting } \\
\text { Recovery Time } \\
\text { (second) }\end{array}$} & \multicolumn{2}{|c|}{$\begin{array}{l}\text { Spontaneous } \\
\text { Fluctuation } \\
\text { (Numbers) }\end{array}$} & \multicolumn{2}{|c|}{$\begin{array}{c}\text { Emotional } \\
\text { Resilience } \\
\text { (Scores) }\end{array}$} & \multicolumn{2}{|c|}{$\begin{array}{l}\text { Emotional } \\
\text { Constriction } \\
\text { (Scores) }\end{array}$} & \multicolumn{2}{|c|}{$\begin{array}{c}\text { Symmetry in } \\
\text { Visuomotor } \\
\text { Coordination } \\
\text { (percentage) }\end{array}$} \\
\hline & M & SD & $M$ & SD & M & SD & M & SD & M & SD & M & SD & $M$ & SD \\
\hline Gr. A & .26 & .08 & 7.43 & 1.59 & 3.2 & 2.3 & 03 & 1.1 & 16.3 & 3.47 & 7.8 & 2.5 & 477.8 & 10.5 \\
\hline Gr. B & .30 & .17 & 1.21 & 1.38 & 8.9 & 7.1 & 10 & 7.1 & 11.2 & 4.58 & 10.2 & 3.21 & 19.2 & 23.21 \\
\hline Gr. C & .38 & .09 & 0.75 & 1.85 & 14.9 & 6.12 & 12 & 3.3 & 6.75 & 5.05 & 14.3 & 4.11 & 29.9 & 11.41 \\
\hline
\end{tabular}




\begin{tabular}{|c|c|c|c|c|c|c|c|}
\hline $\begin{array}{l}\text { KW- } \\
\text { values }\end{array}$ & $25.78^{* *}$ & $22.39^{* *}$ & $11.34^{* *}$ & $17.11^{* *}$ & $14.59^{* *}$ & $19.16^{* *}$ & $26.36^{* *}$ \\
\hline
\end{tabular}

Overall impressions have suggested that the performances of the development group players having moderate level of sympathovagal balance (hereafter Group A performers) have placed themselves way ahead of their counterparts (from both Groups B \& C). These findings clarify the superiority of the players having moderate level of sympathovagal balance not only in the ball-game performance but also in the laboratory-based and performance-based analyses of game-specific behavioural, psychobiological and psychomotor measures, over their counterparts having discordant sympathovagal balance (Group B) as well as players having high-level sympathovagal balance (Group C). Further to add, players of $\mathrm{Gr}$. A have been observed to display marked level of consistency between them, in almost all of the variables measured, while their counterparts have failed to maintain that extent of consistency on

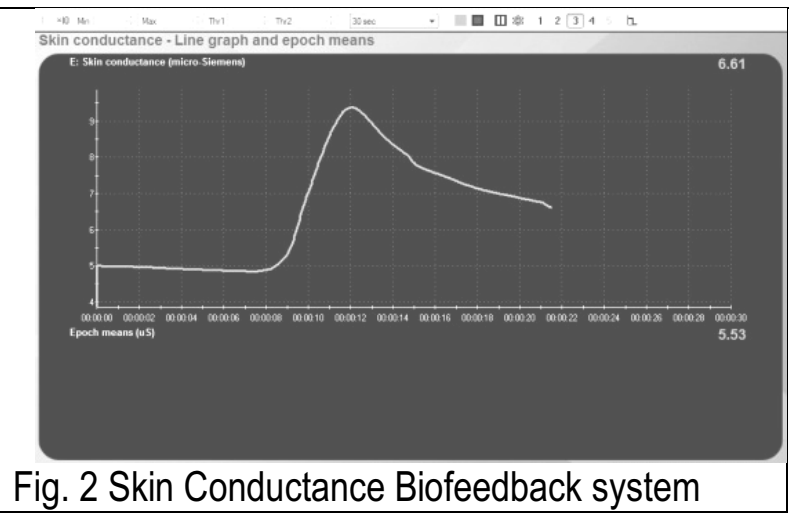
majority of the variables assessed. Compared to the Gr.A players, others ( $\mathrm{Gr}$. B \& C players) lacked in emotional resilience and had more constrictions which was also found corroborated with their unstable psychobiological make-up, which might have been resulted in delayed agility (comprised of delayed reactions as well as movement timings) and perhaps finally contributed in display of lack in coordinated movements. Precisely it is worthy to be mentioned here that, a few of the Gr. A, players were also observed to have delayed response latencies, which have made their group reaction score fairly inconsistent, and hence we also singled out those players who produced delayed agility scores compared to their other group members.

Table - 2 -Model a - Summary of multiple linear regression analysis (in Gr. A players who did not receive any

\begin{tabular}{|c|c|c|c|c|c|}
\hline \multirow{2}{*}{$\begin{array}{l}\text { Dep. Variable - } \\
\text { Symmetric Movement } \\
\text { coordination } \\
\text { (Slower reaction ability) }\end{array}$} & \multicolumn{2}{|c|}{$\begin{array}{l}\text { Unstandardized } \\
\text { Coefficients }\end{array}$} & \multirow{2}{*}{$\begin{array}{c}\text { Standard } \\
\text { Coefficients } \\
\text { Beta }\end{array}$} & \multirow[t]{2}{*}{$\mathrm{t}$} & \multirow[t]{2}{*}{ Sig. } \\
\hline & B & Std. Error & & & \\
\hline (Constant) & 4.387 & .243 & & 18.034 & 0.000 \\
\hline Emotional Resilience & -.103 & .051 & -.077 & -2.011 & $0.045^{*}$ \\
\hline Tonic Skin Conductance & .130 & .028 & .196 & 4.690 & $0.000^{* *}$ \\
\hline Orienting Recovery & .251 & .043 & .255 & 5.793 & $0.000^{* *}$ \\
\hline Spontaneous fluctuation & -.119 & .027 & -.173 & -4.371 & $0.000^{* *}$ \\
\hline
\end{tabular}

$$
(F(3,23)=13.105, P<0.000)) \text { Model Adj. } R^{2}=66.0 \% \text {. }
$$

Multiple linear regressions outcomes were presented from Tables 2 to 4 . Table- 2 explained that, independent variables such as emotional resilience $(p=.045)$, along with measures of tonic skin conductance $(p=.000)$, measure of orienting recovery $(p=.000)$ spontaneous fluctuation $(p=.000)$ can predict $66.0 \%$ of variance changes in the extent of dependent measure of observed poor agility (refer to model a).

Table - 3 -Model $\boldsymbol{b}$ - Summary of multiple linear regression analysis (in Gr. B players who were having discordant sympathovagal balance and who received Sc biofeedback intervention).

Dep. Variable -

Asymmetric and Unstandardized Coefficients
Standard

Coefficients
Sig.

discordant Movement coordination 
SHS Web of Conferences

$\begin{array}{lccccc} & \text { B } & \text { Std. Error } & \text { Beta } & & \\ \text { (Constant) } & 3.564 & .172 & & 20.759 & 0.000 \\ \text { Tonic Skin Conductance } & -.312 & .040 & -.299 & -7.803 & 0.000^{* *} \\ \text { Emotional Constriction } & .101 & .048 & .084 & 2.092 & 0.037^{* *}\end{array}$

$(F(3,24)=21.058, P<0.000))$ Model Adj. $R^{2}=81.0 \%$.

Similarly the multiple linear regression equations (Table -2 , model $\boldsymbol{b}$ ) explained that measures of tonic skin conductance $(p=.000)$ and emotional constriction $(p=.037)$ can predict $81.0 \%$ of variance changes in the extent of dependent measure of delayed movement timing (refer to model $\boldsymbol{b}$ ).

Table - 4 -Model $\boldsymbol{c}$ - Summary of multiple linear regression analysis (in Gr. C players who were having high-level of sympathovagal balance and who received Sc biofeedback intervention).

\begin{tabular}{|c|c|c|c|c|c|}
\hline \multirow{2}{*}{$\begin{array}{l}\text { Dep. Variable - } \\
\text { Symmetric } \\
\text { coordination }\end{array}$} & \multicolumn{2}{|c|}{$\begin{array}{l}\text { Unstandardized } \\
\text { Coefficients }\end{array}$} & \multirow{2}{*}{$\begin{array}{c}\text { Standard } \\
\text { Coefficients } \\
\text { Beta }\end{array}$} & \multirow[t]{2}{*}{$t$} & \multirow[t]{2}{*}{ Sig. } \\
\hline & $B$ & Std. Error & & & \\
\hline (Constant) & 3.085 & .299 & & 10.315 & 0.000 \\
\hline Orienting Recovery & -.115 & .031 & .071 & -2.880 & $0.008^{* *}$ \\
\hline Emotional Resilience & -.093 & .036 & -.116 & -2.558 & $0.011^{* *}$ \\
\hline Tonic Skin Conductance & -.269 & .043 & -.259 & -6.207 & $0.000^{* *}$ \\
\hline $\begin{array}{l}\text { Spontaneous fluctuation } \\
\qquad(\mathrm{F}(2,25)=17.904, \mathrm{P}<0\end{array}$ & $\begin{array}{r}.117 \\
\text { 0)) } \mathrm{Mo}\end{array}$ & $\begin{array}{c}.049 \\
\text { di. } R^{2}=90 \text {. }\end{array}$ & .098 & 2.383 & $0.017^{\star \star}$ \\
\hline
\end{tabular}

Table -3 however summarizes that, independent measures of emotional resilience $(p=.011)$, along with measures of tonic skin conductance $(p=.000)$, measure of orienting recovery $(p=.061)$ spontaneous fluctuation ( $p=.017$ ) can predict as high as $90.0 \%$ of variance changes in the extent of dependent measure of movement deficiency (refer to model $\boldsymbol{c}$ ).

\section{DISCUSSION}

Results of multiple linear regression analyses have consistently justified interrelationships between the psychobiological measures and the created corroborative psychological explanatory behavioural phenomena observed in the participants. Table 2 (model a) reported that psychological as well as psychobiological measures of emotionality together could explain $66 \%$ changes in the variance in the extent of symmetric movement coordination observed in the participants. The model a actually clarified the significance of direct influences of the psychobiological measures such as - tonic skin conductance and orienting recovery on the coordination component of sport behaviour, which was observed as fairly symmetric in the participants in concern. Similarly indirect influences also were observed, wherein both spontaneous fluctuation and emotional resilience were observed to put negative impact on the extent of coordination. Model a actually explained that, when negative influence of emotional resilience was controlled for symmetric movement coordination - higher frequency of spontaneous fluctuation (extent of short-spell and sudden emotional outburst) might have made regulation over autonomic arousal relatively difficult, which had resulted in delayed orienting recovery from sudden emotional upheaval and in consequence had resulted in relative asymmetry in movement coordination. If the players of Group A could avail Sc biofeedback training, they would be able to cope with the heightened emotional upheaval, and hence could display far more symmetric movement coordination.

Similarly model $\boldsymbol{b}$ signified that, when impact of relatively lower tonic skin conductance was regressed for movement timing - higher extent of emotional constriction in the players have been observed to explain $81 \%$ changes in the variance in the extent of asymmetric and discordant movement 
coordination (refer to Table -3). Again model $\boldsymbol{c}$ depicted that, when direct impact of delayed autonomic recovery (orienting recovery in this case) spontaneous fluctuation was controlled for movement deficiency - lower level of emotional resilience and relatively lower control over autonomic arousal (skin conductance hereafter) have been observed to explain $90 \%$ changes in the variance in the extent of movement deficiency in the players having asymmetric and discordant movement coordination. Here we should remember that they were diagnosed as having discordant sympathovagal balance, and hence Sc biofeedback training perhaps was not sufficient enough to produce observable improvement in coordination.

Findings of the afore-mentioned three regression models interestingly implied that, if negative influence of lower-level of emotional resilience was regressed for, moderate level of tonic skin conductance remaining constant, impact of delayed autonomic recovery and higher frequency of spontaneous fluctuation resulted in relative asymmetry and discordance in movement coordination (model a - Table - 2). Regressing lower tonic skin conductance, higher extent of emotional constriction determined delayed movements and asymmetric movement coordination (model $\boldsymbol{b}-$ Table -3 ). But regressing faster orienting recovery, when inhibitive influence of lower-level of emotional resilience was kept constant - lower tonic skin conductance and higher frequency of spontaneous fluctuation explained reasons behind lack in movement coordination, which however got diminished with the Sc biofeedback intervention (model $\boldsymbol{c}$ - Table - 4).

Out of the models so far have been conceived, it could be postulated that, lack in emotional resilience and higher extent of emotional constriction, which have been consistently observed to give rise to emotional overloading, together accompanied by frequent spontaneous fluctuation (outcome of sudden emotional outburst) have put the players having only moderate or lower levels of autonomic regulation into a distressful situation wherein accumulation of autonomic overloading have made autonomic recovery (orienting recovery) vulnerably difficult. Further to that, lower tonic skin conductance accompanied by frequent spontaneous fluctuations might have resulted in reduced orienting reflex, which has always been observed to have inhibitive impacts onto both agility and movement coordination. Since both agility and movement coordination are vital component of successful performance in cricket, those who have been identified as having marked poorer agility had already been under tremendous emotional pressure, which might have put negative feedback onto their level of alertness and attentive performance thereby.

Models $\boldsymbol{b}$ and $\boldsymbol{c}$ however also pointed out that, that the players having poorer sympathovagal balance as well as higher balance had AMPphase2_... considerably lower level of cognitive-perceptual competence and hence had lacked in optimal level of 
mental preparation to cope with the emotional overloading characterised by perceived apprehensions (fig. 3 defined relations between arousal response amplitude and other reaction and coordination aspects). This finding gets further support from the observed findings of delayed orienting recovery, suggesting the fact that majority of the players got succumbed with the apparently threatening emotional upheavals and more so, with lower ability to cope with and regulate abrupt emotionality, they got emotionally constricted. This finding of inhibitive impact of inherent emotionality on agility and movement got supports from those of our previous researches done on both elite and intermediate level of players and other athletes following simulated methodology (Saha and Saha 2008, 2009 and Saha et al. 2012a, b \& c).

Findings of the regression analyses implied the significance of cognitive competence and emotional hardiness as well as resilience (accompanied by contribution of sharp orienting reflex and higher order tonic autonomic regulation) in ensuring high performance in actual competitive situations, wherein presently observed issues related to comparative shortcomings in emotional stability and in concomitant autonomic regulation resulted in sudden emotional changes, which might have put huge inhibitive impacts, that impaired the task-focus in the players and made them cautious and preoccupied with the apprehensions of failures, which further deteriorated their agile reactions and cooridnative performances.

Findings overall also explained the significance of sympathovagal balance onto performance, wherein high frequencies of spontaneous fluctuation and lower autonomic regulation together got the players out of balance with emotional overloading. This finding revealed an interesting fact with regard to significance of considering apprehension of loosing, as a potential detrimental determinant of performance obstacle, as relatively lower sympathovagal balance (evidenced in models $\boldsymbol{a} \boldsymbol{b}$ and $\boldsymbol{c}$ ) resulted in poorer agility, delayed movements and movement deficiencies. This finding is particularly significant since, in course of performance in intense competitive situations perceived tension mounts and the somatic as well as cognitive anxious perceptions give rise to thoraco-lumbar outflow (dominant SNS response) which gets mediated by the behavioural activation system (BAS) (Beauchaine, 2001 \& Malliani et al. 1991).

In sum, it could be claimed that perceived apprehension of loosing on competitive performance outcomes had differential impacts onto the cognitive-emotional competence and SNS modulation capacity, and also onto the sympathovagal balance observed in the delayed recovery and autonomic measure of emotionality in the players. We admit that with application of further rigorous methodology and better options to replicate this study on randomly selected larger samples, paradigms of this experiment would yield more authentic information related to significance of autonomic evaluations on disruptive emotionality in explaining performance outcomes.

\section{CONCLUSION}

Summary of the present study may be presented as:

- Higher orienting autonomic recovery facilitated in coordination performance and in the level of agility in players who did not receive any intervention.

- Higher extent of emotional constriction and more than adequate level of autonomic tonic arousal were observed as important inhibiting factor for discordant and asymmetric coordination performance in the players having problems in sympathovagal balance.

- Players having higher level of sympathovagal balance were observed as benefitted mostly with the skin conductance biofeedback intervention, which in spite of relatively lower-order 
emotional stability and relatively lower regulation in autonomic activation had helped them to have symmetric coordination.

\section{REFERENCES}

Abernethy, B., \& Russell, D.G. (1984). Advance cue utilization by skilled cricket batsmen. Australian Journal of Science and Medicine in Sport, 16(2), 2-10.

Andreassi, J. L. (1966). Skin Conductance and reaction time in a continuous auditory monitoring task. American Journal of Psychology, 79, 470-474.

Beauchaine, T. (2001). Vagal tone, development, and Gray's motivational theory: Toward an integrated model of autonomic nervous system functioning in psychopathology. Development and Psychopathology, 13, 183-214.

Chattopadhyay, P.K. \& Biswas, P. K. (1983). Characteristics of galvanic skin responses in anxious patients and normal subjects. Indian Journal of Clinical Psychology, 10 (1), 159-164.

Chattopadhyay, P. K.; Bond, A. J. \& Lader, M. J. (1975). Characteristics of galvanic skin response in anxiety states. Journal of Psychiatric Research, 12, 265-270.

Crider, A. (1972). Electrodermal labiality and vigilance performance. Psychophysiology, 9, 268 (Abstract).

Eysenck, H. J. (1982). A model for intelligence. New York: Springer-Verlag.

Fowles, D. C. (1988). Psychophysiology and psychopathology: A motivational approach. Psychophysiology, 25, 373-391.

Franken, R. E. (1998). Human Motivation. Brooks/Cole Publishing Company, 511, Forest Lodge Road, Pcific Grove, CA 93950, USA.

Gray, J. A. (1987a). Perspectives on anxiety and impulsivity: A commentary. Journal of Research in Personality, 21, 493-509.

Gray, J. A. (1987b). The psychology of fear and stress. New York: Cambridge University Press.

Heyman, S. R. (1982). Comparisons of successful and unsuccessful competitors: A reconsideration of methodological questions and data. Journal of Sports Psychology, 4, 295-300.

McLeod, P. (1987). Visual reaction time and high-speed ball games. Perception, 16, 49- 59.

McRobert, A., \& Tayler, M. (2005). Perceptual abilities of experienced and inexperienced cricket batsmen in differentiating between left hand and right hand bowling deliveries. Journal of Sports Sciences, 23(2), 190-191.

Müller, S., Abernethy, B., \& Farrow, D. (2006). How do world-class cricket batsmen anticipate a bowler's intention? Quarterly Journal of Experimental Psychology, 59, 2162-2186.

Nideffer, R. M. (1989). Anxiety, attention and performance in sports: theoretical and practical considerations. In. Anxiety in sports: An International Perspective (Eds. D. Hackfort and C. D. Spielberger), Hemisphere, New York, 117-86. 
Penrose, J. M. T., \& Roach, N. K. (1995). Decision making and advanced cue utilisation by cricket batsmen. Journal of Human Movement Studies, 29, 199- 218.

Renshaw, I., \& Fairweather, M. M. (2000). Cricket bowling deliveries and the discrimination ability of professional and amateur batters. Journal of Sports Sciences, 18, 951-957.

Saha S., Mukhopadhyay Pritha, Chattopadhyay P. K., Biswas D., \& Saha Srilekha. (2005a). Arousal modulation as predictor of achievement motivation in high soccer performers. Reading in Sports Psychology. Jitendra Mohon and Meena Sehgal (Eds.) Friends Publications, India, 116-146.

Saha, S. \& Saha Srilekha. (2001). Cognitive approach to motivation and high soccer performance. Bangladesh Journal of Sports Science, 1(2), 95-108.

Saha, S., Saha Srilekha \& Sharmeen Nushrat. (2003). Bilateral asymmetry in the psychological processes as a function of inhibited sport performance. Journal of Sports and Exercise Psychology, 25, 114-115.

Saha, S., Saha Srilekha \& Sharmeen Nushrat. (2005b). Psychophysiological approach to reaction ability and high sports performance- An exploratory study. Journal of Sports and Exercise Psychology, 27, 132-133.

Singer, R. N. (1988). Psychological testing: What value to coaches and athletes? International Journal of Sports Psychology, 19, 87-106.

Suzuki, S., et. al. (1988). Analysis of the goalkeeper's diving motion, in Science and Football (eds T. Reilly. A. Lees, K. Davids and W. J. Murphy), E. \& F. N. Spon, London, 468-475.

Tenenbaum, G., Levi-Kolker, N., Bar-Eli, M. \& Sade, S (1992). Psychological selection of young talented children for sport. [Book Analytic] In Proceedings of the International Conference on Computer Applicationsin Sport and Physical Education, January 2-6, 1992, (Netanya),The E.Gill Publ. House : Wingate Institute for P. E. and Sport : The Zinman College of P. E., 268-274.

Togari, H. \& Takahashi, K. (1977). Study of 'whole-body reaction' in soccer players. Proceeding of the Department of Physical Education (College of General Education, University of Tokyo), $11,35-41$.

Wegner, \& J. W. Pennebaker (1996) (Eds.), Handbook of mental control, 1-12. Englewood Cliffs, NJ: Prentice Hall.

Alderson, G. J. K., Sully, D. J., \& Sully, H. G. (1974). An operational analysis of one-handed catching task using high speed photography. Journal of Motor Behaviour, 6, 217-226.

Beauchaine, T. (2001). Vagal tone, development, and Gray's motivational theory: Toward an integrated model of autonomic nervous system functioning in psychopathology. Development and Psychopathology, 13, 183-214.

Franken, R. E. (1998). Human Motivation. Brooks/Cole Publishing Company, 511, Forest Lodge Road, Pcific Grove, CA 93950, USA. 
Heyman, S. R. (1982). Comparisons of successful and unsuccessful competitors: A reconsideration of methodological questions and data. Journal of Sports Psychology, 4, 295-300.

Land, M.F., \& McLeod, P. (2000). From eye movements to actions: how batsmen hit the ball. Nature Neuroscience, 3, 1340-1345.

Malliani A., Pagani M., Lombardi F. and Cerutti, S. (1991). Cardiovascular neural regulation explored in the frequency domain. Circulation, 84, $482-492$.

McLeod, P. (1987). Visual reaction time and high-speed ball games. Perception, 16, 49- 59.

Regan, D. (1997). Visual factors in hitting and catching. Journal of Sports Sciences, 15, 533-558.

Saha S., Mukhopadhyay Pritha, Chattopadhyay P. K., Biswas D., \& Saha Srilekha. (2005a). Arousal modulation as predictor of achievement motivation in high soccer performers. Reading in Sports Psychology. Jitendra Mohon and Meena Sehgal (Eds.) Friends Publications, India, 116146.

Saha Soumendra and Saha Srilekha (2008). Sympathovagal balance as moderator of performance excellence in sports. Bang. Journal of Sports Science, 8 (1), 47- 60.Saha Soumendra and Saha Srilekha (2009). Emerging Psychobiological Factors Predicting Performance Excellence in Soccer. 90 minutes Valerian Soccer Foundation Journal, 1(2), 51 - 68.

Saha, S., Saha Srilekha \& Sharmeen Nushrat. (2005b). Psychophysiological approach to reaction ability and high sports performance- An exploratory study. Journal of Sports and Exercise Psychology, 27, 132-133.

Saha, S., Saha Srilekha; Chowdhury, D.; Fahim N. A \& Salah Uddin M. (2012a). In search of predictors for reaction ability related to high performance in Cricket. Social Science International, 28 (1), 1 -18 .

Saha, S., Saha, Srilekha; Chowdhury, D.; Fahim N. A \& Salah Uddin M. (2012b). Action Regulation as Predictor of High Performance in Cricket. Shodh Sangam, January Special Issue, 211-15.

Saha Srilekha, Saha, S., Krasilschikov O., Ismail, M. S. (2012c). Predictive Structural Analysis in explaining Reaction Ability as a Mediator for Performance Excellence in Malaysian Athletes. Akash, 105-113.

Tenenbaum, G., Levi-Kolker, N., Bar-Eli, M. \& Sade, S (1992). Psychological selection of young talented children for sport. [Book Analytic] In Proceedings of the International Conference on Computer Applications in Sport and Physical Education, January 2-6, 1992, (Netanya), The E. Gill Publ. House : Wingate Institute for P. E. and Sport : The Zinman College of P. E., 268-274.

\section{ACKNOWLEDGEMENT}

Dr. Soumendra Saha was supported by a Ministry of Higher Education research Grant (KPT Sport Research Grant - Perincian Geran Penyelidikan Tajaan Agensi Luar - KPT (Bhg. Sukan) (304/PPSK/6150128/K134). Authors of the present study are indebted to the Grant Authorities for having awarded to carry out the study. 